\title{
A Chinese mitten crab Eriocheir sinensis from the River Clyde - the first record of this invasive, non-native species in Scotland
}

\author{
William E. Yeomans ${ }^{1 *}$ and John Clark ${ }^{2}$
}

\begin{abstract}
The remains (probably a moult) of a female Chinese mitten crab were found in the freshwater River Clyde. This is the first report of a Chinese mitten crab from the wild in Scotland and is well outside the previously recorded range of the species in Great Britain. The origin of this specimen remains enigmatic but this finding has potentially serious implications for the Clyde catchment, the biota of which is recovering from centuries of poor water quality and structural modification. Work is now required to determine whether the Clyde has been colonised by the Chinese mitten crab and, if so, to establish the size of the resident population, its associated threat to local biodiversity and the implications for river management under the European Union Water Framework Directive.
\end{abstract}

Keywords: Invasive, Non-native, Alien, Chinese mitten crab, Freshwater, Scotland, Great Britain, United Kingdom

\section{Introduction}

The Chinese mitten crab, Eriocheir sinensis H. Milne Edwards, 1853 is native to east Asia but has spread to such an extent that it is listed among the 100 most invasive and undesirable species in the world (Lowe et al. 2004; de Lafontaine 2005). The United Kingdom Technical Advisory Group for Alien Species, which provides guidance relating to the use of non-native species in Water Framework Directive waterbody classification, has placed E. sinensis on the "High Impact List" of aquatic, non-native species. It identified this species as having the potential to impact freshwater, transitional and coastal environments and species. The adult crab breeds in estuaries and the newly-settled juveniles migrate into freshwater where they spend the majority of their life (3-5 years) before migrating downstream again when sexually mature to spawn and subsequently die. The history of the Chinese mitten crab in the British Isles and beyond has been reviewed by Clark et al. (1998); Herborg et al. (2003, 2005, 2007); Gilbey et al. (2008); and Dittel and Epifanio (2009). Eriocheir sinensis is the only crab species currently likely to be found in

\footnotetext{
* Correspondence: william.yeomans@glasgow.ac.uk

${ }^{1}$ Clyde River Foundation, Graham Kerr Building, University of Glasgow,

Glasgow G12 8QQ, Scotland, UK

Full list of author information is available at the end of the article
}

freshwaters in the British Isles; known associated negative economic and ecological impacts elsewhere are largely due to its habit of burrowing into soft banks, its catholic diet, and the disruption caused to fishing and irrigation activities during the spawning migration (Dittel and Epifanio 2009). Pre-invasion data from native ecosystems is often absent, making the ecological impacts of mitten crab invasion poorly understood (Gilbey et al. 2008) although comprehensive risk assessments do exist (e.g. Buoma and Soes 2010).

\section{Materials and methods}

Data from a number of recording initiatives have been pooled by others to determine the national picture of Chinese mitten crab distribution in Great Britain. Until now, there have been no records of $E$. sinensis from Great Britain north of the River Tyne on the east coast, and the Duddon Estuary in Cumbria on the west coast (http://mittencrabs.org.uk/distribution) (Fig. 1).

\section{Results}

The remains (probably a moult) of a female Chinese mitten crab were recovered by Mr John Clark from the "Skurlie Pool" on the River Clyde in western Scotland at United Kingdom National Grid Reference NS 63042 62514 [Lat 55 50' 10.122"; Long $-4^{\circ} 11^{\prime} 18.118^{\prime \prime}$ ] on 


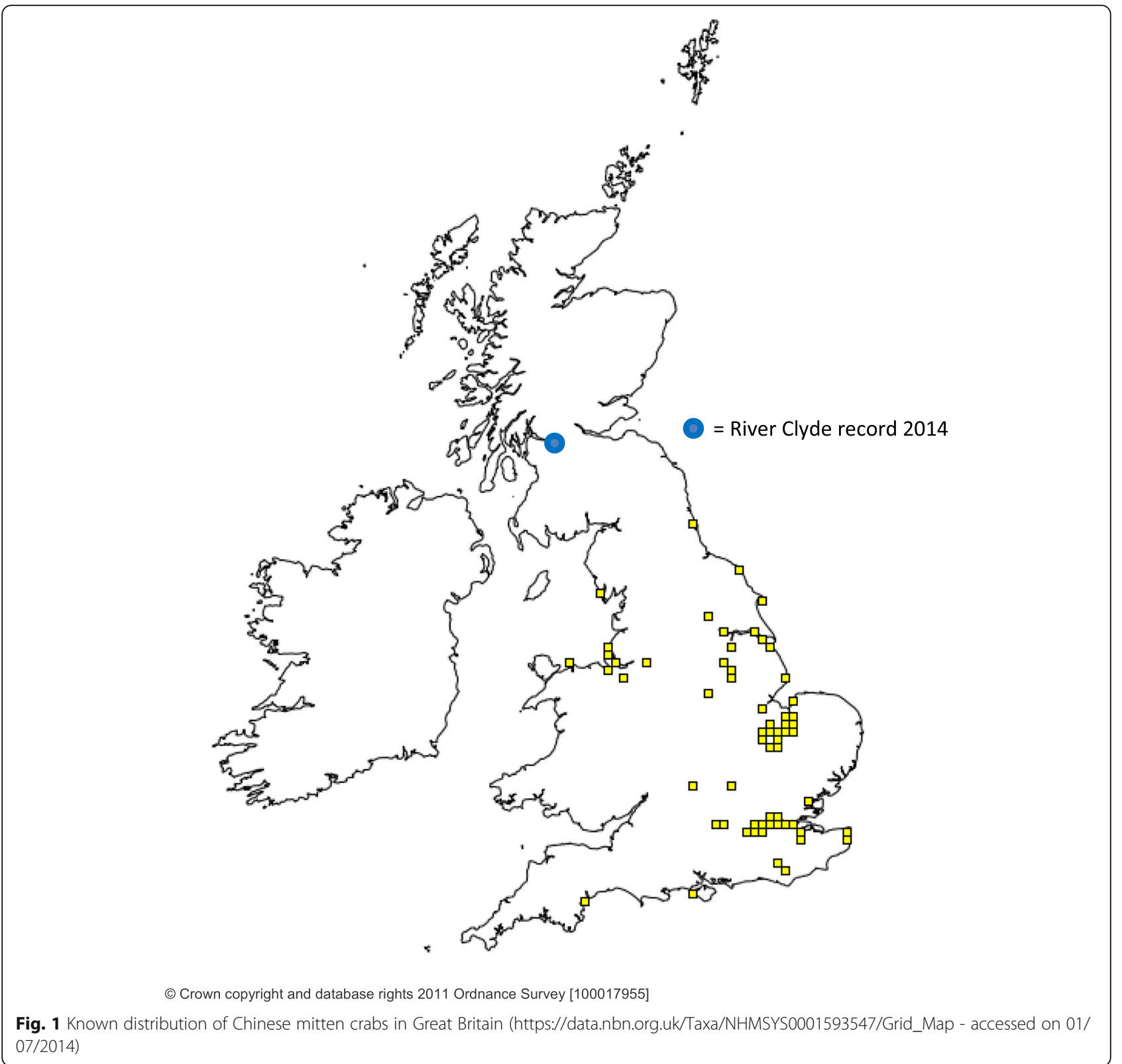

23 June 2014 (Fig. 1). The river forms the boundary between the City of Glasgow and the County of South Lanarkshire at this point, approximately $4 \mathrm{~km}$ above the limit of salt water penetration (Dalmarnock Roadbridge). The affected reach is still influenced by freshwater backing up during high Spring tides. The remains were discovered in a complete state but disaggregated when removed from the water. It was identified as a female because the setal mats on the chela did not completely circumvent the propodus, as is the case with male crabs (Paul Clark, pers. comm.). Many of the hard parts were recovered, although the carapace and underside fractured into several pieces, making it impossible to measure the carapace width to give an accurate indication of the size of the crab. The remains (largely claws, legs and fragments of carapace; Fig. 2) were passed to the Clyde River Foundation for confirmation of identification on 25 June 2014 and a second opinion was received on photographic evidence from Paul Clark (Natural History Museum, London) on 26 June 2014 (Fig. 3). The remains were initially preserved in $80 \%$ Industrial Methylated Spirit solution by the Clyde River Foundation, and subsequently $80 \%$ ethanol when lodged with The Hunterian (Zoology Museum) at the University of Glasgow (Entry Number 1424) on 3 July 2014. 


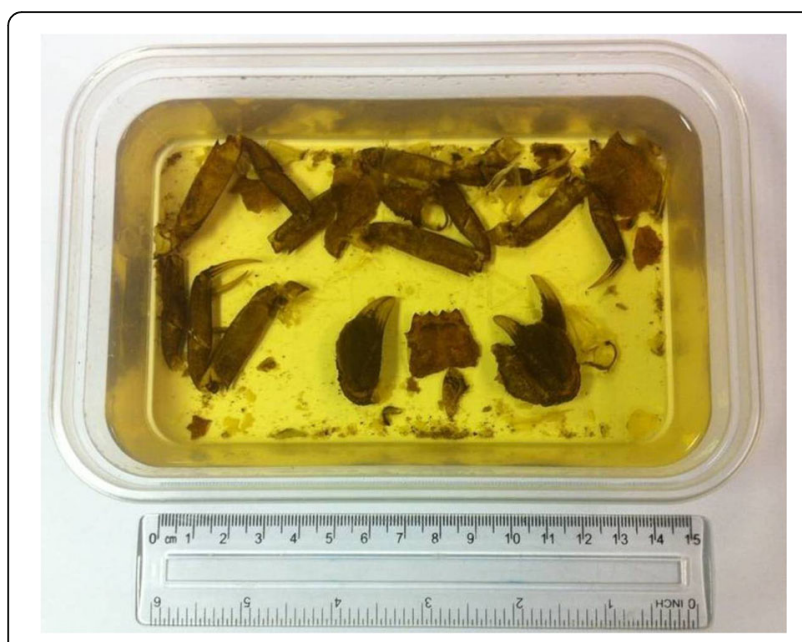

Fig. 2 Chinese mitten crab remains recovered from the River Clyde on 22 June 2014

\section{Discussion}

Large areas worldwide are vulnerable to invasion by Chinese mitten crabs because of the size and distribution of the existing populations, and the high reproductive rate and wide range of physiological tolerances of the species (Herborg et al. 2007; Gilbey et al. 2008; Dittel and Epifanio 2009). The Firth of Clyde and the Clyde Estuary are busy with international and coastal shipping, and pleasure boating is possible into Glasgow city centre. The Clyde system is therefore likely to be susceptible to extensive colonisation by $E$. sinensis, with potentially serious consequences for the native aquatic biodiversity in watercourses already under threat from invasive, nonnative species like North American signal crayfish, Pacifastacus leniusculus (Dana, 1852) and European bullhead, Cottus gobio Linneus, 1758 (Crawford et al. 2006; Gladman et al. 2009; Yeomans and Gladman 2011; Clyde

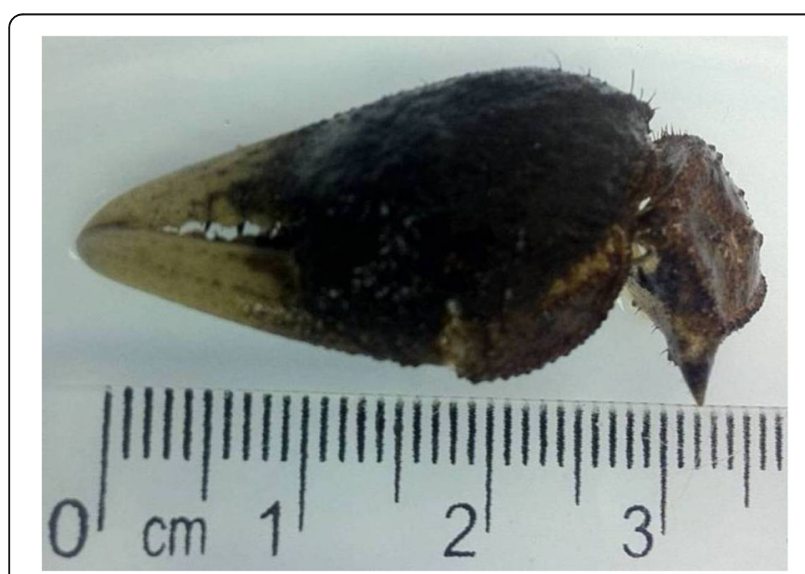

Fig. 3 Claw of female Chinese mitten crab recovered from the River Clyde on 22 June 2014
River Foundation, unpublished data). In the case of the River Clyde and tributaries, the recent return of the previously extirpated Atlantic salmon (Salmo salar Linneus, 1758) and its associated fishery could be jeopardised, as could the culturally valuable fisheries for brown trout, Salmo trutta Linneus, 1758 and European grayling, Thymallus thymallus (Linneus, 1758); the latter a species introduced to the Clyde catchment during the $19^{\text {th }}$ Century. Sub-adult Chinese mitten crabs have been demonstrated to feed on a variety of fish eggs under laboratory conditions (Jessica Webster, David Morritt \& Paul Clark, pers. comm.). Locally, the River Leven links Loch Lomond to a shared estuary in the Firth of Clyde, which makes the internationally-important biodiversity and natural heritage associated with the loch and its tributaries also potentially vulnerable to invasion and damage. The River Leven also links the Clyde Estuary to the Endrick Water Special Area of Conservation and Site Of Special Scientific Interest, a site which is classified for its Atlantic salmon and rare freshwater resident river lamprey, Lampetra fluviatilis (Linneus, 1758) populations.

This report, therefore, considerably expands the known British range of the Chinese mitten crab and is the first record of a specimen from the wild in Scotland. There is, however, some uncertainty about the origin of the specimen, principally because it was probably a moult. Herborg et al. (2005) highlighted the inevitability of E. sinensis spreading along the west coast of the United Kingdom and the potential mechanisms for spread include advective movement of planktonic larvae in coastal waters; the transfer of larvae, juveniles or adults in ships' ballast water; natural transfer and/or the human-mediated transfer of adults in the live food trade (Herborg et al. 2007). Given the relative isolation of the Clyde from the other UK populations, it seems unlikely that the crab arrived there by natural means, rather either from hull fouling or by human-mediated movement.

The precise nature of the introduction is likely to remain enigmatic but inward transfer in ballast water cannot be ruled out. It is an offence under Section 14 of the Wildlife and Countryside Act 1981 (as amended) in Scotland "for any person to release, allow to escape from captivity or otherwise cause any animal outwith the control of any person to be at a place outwith its native range"; which makes it illegal to release Chinese mitten crabs to the wild. It is not, however, currently illegal to sell live Chinese mitten crabs (http://www.scotland.gov.uk/Topics/Environment/Wildlife-Habitats/InvasiveSpecies/legislation). Live mitten crabs have been sold in Glasgow in recent times (Colin Bean, pers. comm.).

The chance that the crab was deliberately released to the river cannot be discounted, and there is evidence from elsewhere that such introductions have taken place in order to initiate commercial fisheries or even as part 
of religious rituals (Shiu and Stokes 2008). The Clyde mitten crab was also found in the vicinity of an illegal eel trap, which leads to the consideration that the crab could either have been used to bait the trap or that it was caught in the trap and discarded by the trapper back into the river. In the former case, it is likely that alternative baits (e.g. fish) would be more commonly used; if the latter is true, then such traps may provide a mechanism for future monitoring of the extent and density of the population. Furthermore, the possibility that the remains were planted as a hoax has been considered and rejected because the area where they were found is relatively inaccessible and the prospect of detection before complete decomposition was considered small. The River Clyde also has one of the most urban Atlantic salmon fisheries in the world, and such a hoax is more likely to have been carried out in a more accessible, busier location.

It is important however, in the absence of further live specimens, not to place too much emphasis on this single occurrence. Rudnick et al. (2003) document cases from areas in North America where " $a$ few" Chinese mitten crabs have been collected but where self-sustaining populations were not established. The River Clyde is relatively large at the sampling point and the probability of a solitary individual being found is low, which suggests an established population but one which has escaped detection thus far. Low densities of crabs at the upstream edges of populations make detection difficult (Rudnick et al. 2003) and an assessment of the claw size (Fig. 3) suggests that this specimen was an immature animal. Given that mature crabs migrate downstream in the autumn and winter and their immature conspecifics migrate upstream in spring (Herborg et al. 2005), it appears likely that this individual was either resident or migrating upstream.

The value of a monitoring scheme for E. sinensis has been well demonstrated on the River Thames in England (Clark et al. 1998). Herborg et al. (2005) also emphasised the importance of monitoring around rare records such as this because of potentially rapid future population increase under more favourable conditions and/or the exceedance of a critical population density.

This may be a rare opportunity to document the dynamics of a Chinese mitten crab invasion in Great Britain from a relatively small population and this is not purely of academic interest. The site from where the carcass was recovered is within the "River Clyde (North Calder to Tidal Weir)" waterbody as described for the European Union Water Framework Directive legislation (http://ec.europa.eu/environment/water/water-framework/index_en.html).

For water management purposes, this waterbody is currently classified under the Water Framework Directive as being of "Poor Ecological Potential with overall ecological status of Poor". The overall status comprises many tiers of classification data and the component for "Alien Species" in the waterbody is "High" currently (i.e. free of the nonnative species which are considered to negatively impact this parameter). The presence of a self-sustaining population of Chinese mitten crabs would also reduce that component of the overall classification. For that reason, this record will be followed by an intensive site-specific search for live mitten crabs. If that proves positive, a long-term monitoring programme for E. sinensis in the River Clyde system should be implemented, aimed specifically to describe the size and distribution of the population and to quantify its interaction with native biological communities. When the extent of the Clyde population is known, options for its containment and control can be considered. For example, the issues and practicalities surrounding commercial exploitation as a means to deplete an English E. sinensis population have already been examined (Clark et al. 2008; Clark 2011).

\section{Acknowledgements}

David Bailey, Colin Bean, Paul Clark and Phil Rainbow provided comments on an early manuscript. Katriona Lundberg clarified some aspects of the Water Framework Directive status of the Chinese mitten crab in the Clyde catchment.

\section{Funding}

The work was funded privately from Clyde River Foundation resources.

\section{Authors' contributions}

$J C$ discovered the remains of the specimen and was involved in the drafting of the manuscript. WY wrote the manuscript. Both authors read and approved the final manuscript.

\section{Competing interests}

The authors declare that they have no competing interests.

\section{Consent for publication}

The authors freely consent to the publication of this paper. All data associated with this publication are contained herein; the specimen was deposited at The Hunterian (Zoology Museum) at the University of Glasgow (Entry Number 1424) on 3 July 2014

Ethics approval and consent to participate

No ethical approval or consent to participate was required.

\section{Author details}

${ }^{1}$ Clyde River Foundation, Graham Kerr Building, University of Glasgow, Glasgow G12 8QQ, Scotland, UK. ${ }^{2} 11$ Kildary Avenue, Glasgow G44 3AX Scotland, UK.

Received: 11 November 2016 Accepted: 14 November 2016 Published online: 05 December 2016

\footnotetext{
References

Buoma S, Soes DM. A risk assessment of the Chinese mitten crab in The Netherlands. Bureau Wartenberg bv for Ministry of Agriculture, Nature and Food Quality, Wageningen, Project 09-772. 2010. p. 51.

Clark PF. The commercial exploitation of the Chinese mitten crab Eriocheir sinensis in the River Thames, London: damned if we don't and damned if we do. In: Galil BS, Clark PF, Carlton JT, editors. In the wrong place - alien marine crustaceans: distribution, biology and impacts. Invading nature Springer series in invasion ecology, vol. 6. London: Springer Science and Business Media; 2011. p. 537-80.

Clark PF, Rainbow PS, Robbins RS, Smith B, Yeomans WE, Thomas M, Dobson G. The alien Chinese mitten crab, Eriocheir sinensis (Crustacea: Decapoda: Brachyura), in the Thames Catchment. J Mar Biol Assoc UK. 1998;78:1215-21.
} 
Clark PF, Campbell P, Smith B, Rainbow PS, Pearce D, Miguez RP. The commercial exploitation of Thames mitten crabs: a feasibility study. A report for The Department for Environment, Food and Rural Affairs by the Department of Zoology, The Natural History Museum, London. DEFRA Reference FGE 274. Pp1-81 + Appendices 1-6. 2008.

Crawford L, Yeomans WE, Adams CE. The impact of introduced signal crayfish Pacifastacus leniusculus on stream invertebrate communities. Aquat Conserv. 2006;16:611-21.

De Lafontaine Y. First record of the Chinese Mitten Crab (Eriocheir sinensis) in the St. Lawrence River, Canada. J Great Lakes Res. 2005;31:367-70.

Dittel Al, Epifanio CE. Invasion biology of the Chinese mitten crab Eriocheir sinensis: A brief review. J Exp Mar Biol Ecol. 2009;374:79-92.

Gilbey V, Attrill MJ, Coleman RA. Juvenile Chinese mitten crabs (Eriocheir sinensis) in the Thames estuary: distribution, movement and possible interactions with the native crab Carcinus maenas. Biol Invasions. 2008:10:67-77.

Gladman Z, Adams C, Bean C, Sinclair C, Yeomans W. Signal crayfish in Scotland. In: Brickland J, Holdich DM, Inhoff E, editors. Crayfish Conservation in the British Isles. Proceedings of a Conference held on $25^{\text {th }}$ March 2009 in Leeds, UK. 2009. p. 43-8.

Herborg L-M, Rushton SP, Clare AS, Bentley MG. Spread of the Chinese mitten crab (Eriocheir sinensis H. Milne Edwards) in Continental Europe: analysis of a historical data set. Hydrobiologia. 2003:503:21-8.

Herborg L-M, Rushton SP, Clare AS, Bentley MG. The invasion of the Chinese mitten crab (Eriocheir sinensis) in the United Kingdom and its comparison to continental Europe. Biol Invasions. 2005;7:959-68.

Herborg L-M, Rudnick DA, Siliang Y, Lodge DM, Maclsaac HJ. Predicting the range of Chinese mitten crabs in Europe. Conserv Biol. 2007;21:1316-23.

Lowe S, Browne M, Boudjelass S, De Poorter M. 100 of the World's Worst Invasive Species Database. Published by The Invasive Species Specialist Group (ISSG), a specialist group of the Species Survival Commission (SSC) of the World Conservation Union (IUCN); 2004. p. 12

Rudnick DA, Hieb K, Grimmer KF, Resh VH. Patterns and processes of biological invasion: the Chinese mitten crab in San Francisco Bay. Auckland: Basic Appl Ecol. 2003:4:249-62.

Shiu H, Stokes L. Buddhist animal release practices: historic, environmental, public health and economic concerns. Contemporary Buddhism. 2008;9:181-96.

Yeomans WE, Gladman Z. North American signal crayfish, Pacifastacus leniusculus (Dana) in the River Kelvin, Glasgow. The Glasgow Naturalist. 2011;25:104-5.

\section{Submit your next manuscript to BioMed Central and we will help you at every step:}

- We accept pre-submission inquiries

- Our selector tool helps you to find the most relevant journal

- We provide round the clock customer support

- Convenient online submission

- Thorough peer review

- Inclusion in PubMed and all major indexing services

- Maximum visibility for your research

Submit your manuscript at www.biomedcentral.com/submit 